\title{
Modelling the system dynamics of islanding asynchronous generators
}

\author{
Håkon Molland Edvardsen \\ Oslo, Norway \\ haakky1@gmail.com
}

\author{
Dietmar Winkler \\ Telemark University College, Norway \\ dietmar.winkler@hit.no
}

\begin{abstract}
Asynchronous generators are often used for small hydro power stations with an installed power capacity of under $1 M W$. The reason for this is their robustness and low cost. In order do be able to produce active electrical power with an asynchronous generator once needs to provide enough excitation by means of reactive power provided by either the electrical grid or additional capacitors.

But in asynchronous generators we can also find the phenomenon of self-excitation which allows the asynchronous generator to operate as a standalone unit. Investigation of the self-excitation process shows that significant over-voltages can occur if a generator with sufficient capacitors is suddenly disconnected from the utility grid. The precondition for a successive voltage build-up is that the generator is left with enough capacitive power and a low load after the disconnection.

The Lønnestad radial in Seljord, Norway, is a distribution radial with both asynchronous and synchronous generators connected. In order to investigate the system dynamics in the radial after it is disconnected from the rest of the $22 \mathrm{kV}$ distribution grid, the radial was modelled and simulated using Modelica as modelling language.
\end{abstract}

Keywords: modelica, asynchronous generators, self-excitation, islanding, electric power library

\section{Introduction}

The main share of the electricity produced in Norway is based on utilisation of the nation's large potential of hydro power. Today are nearly all the large waterfalls profitable for hydro power production already utilised, or protected against encroachment on nature. Due to this, there has for the last decades been an expansion in the number of small hydro power stations below $10 \mathrm{MW}$. This is often minor projects where the power station is located near a small waterfall owned by a local landowner.

These small hydro power stations are often connected to already existing distribution grids, due to the geographical location and installed capacity of these stations. This is often grids constructed for low capacities with purpose to distribute the electricity out to the local consumers. Connection of power stations in these types of grids will therefore often change the situation of power flow in the grid, and lead to challenges regarding voltage stability and requirements for faults detection.

\section{Theory}

The system that will be described in this paper consists of a electrical distribution radial to which one synchronous generator and several asynchronous generators are connected. This theory section will only cover the most important aspects of the complex power systems.

\subsection{Asynchronous generators}

In the industry the asynchronous machine, or induction machine, is used in a wide variety of applications with purpose of converting electrical power to mechanical work. The asynchronous machine is very economical, reliable, and easy to control, which are some of the reasons for its popularity. There are two main types of asynchronous machines based on the rotor construction; squirrel cage type, and wound rotor type. The simplicity and low cost, and the fact that they can be driven as a generator as well as a motor, makes these machines very beneficial for wind power generation and small hydro power stations up to $1 M W$.

Unlike in wind power applications, the wound generator is seldom used in small hydro power stations. The reason for this is that generators used in small hydro power stations generally is operated on the 
principle of self-excitation without any rotor excitation. For such applications, generators with the squirrel cage rotors can with advantage be used instead of generators with wound rotor, since the squirrel cage machine has lower cost.

\subsubsection{The phenomena of self-excitation}

Unlike the synchronous generator which gets its magnetisation from an internal magnetising source, and can be controlled to operate at a given frequency, the induction generator has no independent control over the air-gap field. The induction generator needs lagging reactive power to produce the main air-gap and winding leakage flux [1]. This phenomenon is referred to as self-excitation since the generator achieves its magnetising from a grid, or capacitors which are connected to the stator terminals. The phenomena permit utilisation of an induction generator as a standalone unit without a voltage source connected. Due to this the induction generator is often referred to as a SEIG (Self-Excited Induction Generator).

The phenomenon of self-excitation has been known for a long time, and a great deal of research has been done in the field of describing the phenomena and its transient behaviour. Various types of models have been proposed, but the main part of them is rather complicated models expressed by the Park's transform[2].

Initiation of the self-excitation process Selfexcitation of a standalone generator may take place if a sufficient amount of capacitors is connected to the generator. In order to initiate the self-excitation process, the residual flux in the rotor iron has to be high enough. The residual flux will induce a voltage in the stator when the generator is accelerated to a certain speed. By connecting capacitors to the terminals of the generator, the induced stator voltage will cause a flow of current from the stator [3].

For a given capacitor, an SEIG running at no load requires only a minimum speed for the self-excitation to initiate [4].

Voltage build-up in the generator Once the process of self-excitation is initiated, the generator voltage builds up. The voltage build up can more easily be understood by looking at the phasor diagram in Figure 1.

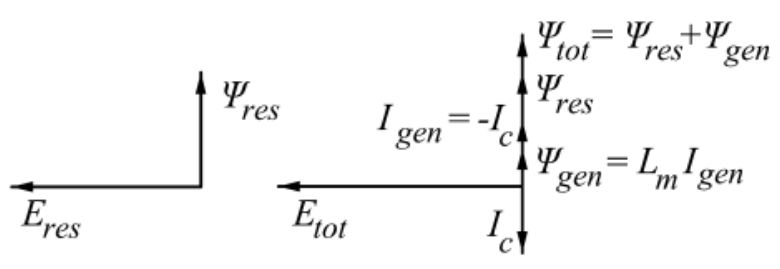

Figure 1: Phasor diagram before and after the selfexcitation is initiated [3]

In this figure it can be observed that a current, $I_{c}$, starts to flow from the capacitors once the selfexcitation is initiated. This current generates a flux, $\Psi_{g e n}$, into the generator, with the same direction as the residual flux, $\Psi_{\text {res }}$. Therefore, the current, $I_{g e n}$, circulating in the stator reinforces the total flux, $\Psi_{\text {total }}$. This reinforced total flux causes an even higher stator voltage leading to successive increase in current and flux [3].

Figure 2 shows the generator magnetising characteristic and capacitance for three different frequencies, where the machine magnetising characteristic is simplified by linear segments with a knee point.

For a given capacitance and generator saturation characteristic, the intersection of the capacitance line and the V-I-curve of the generator moves as the frequency increases. The voltage build-up comes to halt when the non-linear magnetisation curve for the generator intersects the capacitor voltage curve [1]. This point is the steady state operating point for an induction generator running at no-load with capacitors connected. The no-load steady state operating point is determined by the non-linear magnetisation curve of the generator, the value of the capacitors, and the speed of the generator.

Figure 2 shows that by increasing the frequency, the generator curve is moved upwards, while the slope of the capacitor curve decreases, which results in an increase of steady state operation voltage. This states that connection of capacitors supplying a no-loaded induction generator with a larger reactive power than needed may cause over-voltage at the generator terminals [3].

The intersection point between the saturation characteristic and the capacitor line can be defined in terms of the electrical frequency [1]: 


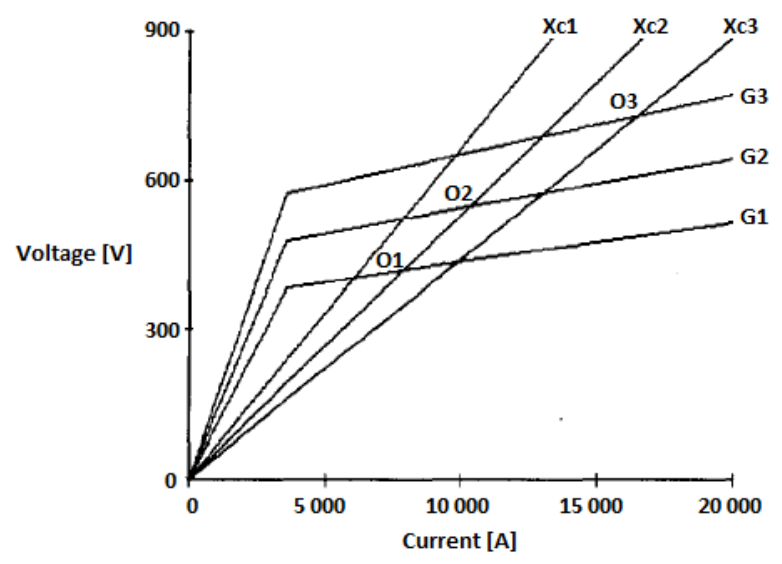

Figure 2: V-I curves for induction generator and capacitor at different frequencies [11]

$$
\begin{aligned}
V(\omega) & =\frac{\omega A}{1-\omega^{2} L_{d} C} \\
I(\omega) & =\frac{\omega^{2} A C}{1-\omega^{2} L_{d} C}
\end{aligned}
$$

Where $L_{d}$ is the non-linear magnetisation inductance defined as $\mathrm{d} \Psi / \mathrm{d} l$ on the saturated portion of the no-load $\Psi-I$ curve for the generator, and $A$ is the interception of the dynamic inductance line with the ordinate, defined as $\Psi(I)=A+L_{d} I$.

In order to achieve a steady state operation point at any frequency, the capacitance must satisfy the following expression:

$$
\frac{L_{a}}{\omega^{2} L_{d}}>C>\frac{1}{\omega^{2} L_{a}}
$$

Where $L_{a}$ is the inductance defined by the air-gap line of the generator. [1]

\subsection{Synchronous generators}

Three phase synchronous generators are the primary source for all the electric energy produced in a power system. One of the reasons is that the synchronous generator gives the opportunity to decide whether it is desirable to produce or consume reactive power, which gives us the ability to regulate the voltage and power flow in an interconnected grid [5].

The rotor contains a field winding which is supplied by a DC source. This voltage results in a field current, $I_{x}$, which produce the rotor field in the airgap between the rotor and stator. Controlling the rotor current and hence the rotor produced field, makes it possible to regulate the induced emf and the reactive power of the generator.

\subsection{Transmission lines}

Small hydro power stations are often connected to a local distribution grid. This grid is usually owned by the local utility company, and is normally operated at a voltage level between $11 \mathrm{kV}$ and $22 \mathrm{kV}$.

A distribution grid is normally composed of a combination of overhead lines and underground cables. The overhead lines are used for long distances and rural areas, while underground cables are used in urban areas and for underwater crossings. An underground cable is 10 to 15 times more expensive than an overhead line, and it is therefore only used in situations where overhead lines are unsuitable.

From a mathematical point of view, an underground cable can be modelled in exactly the same way as an overhead line. Here, the values of the electrical parameters are the only difference between them. In a cable, the shunt capacitance is strongly dependent on whether the three-phase conductors are screened or not, and on whether the three conductors constitute separate three-phase cables or one common cable [6].

The typical per unit length series inductance, $L$, of a cable is about half the inductance of a similar rated overhead line. On the other hand, the per unit length charging current is about 30 times more than for a similar rated overhead line. For a critically long cable, the charging current can be equal to the maximum current of the cable, there will then be no capacity left for transmission of power.

\section{Over-voltage phenomena in Grunnåi}

On the $27^{\text {th }}$ July in 2011, several unwanted events took place in Grunnåi power station. By looking at the damages it could be seen that significant overvoltages had occurred in the $22 \mathrm{kV}$ busbars of the power station.

\subsection{Damages from the events}

On the end termination of one of the incoming supply cables, a phase to ground fault had occurred. Two pictures of the end termination and its damage are shown in Figure 3. From the figure it can be seen 
that there has been heat generation in the end termination.
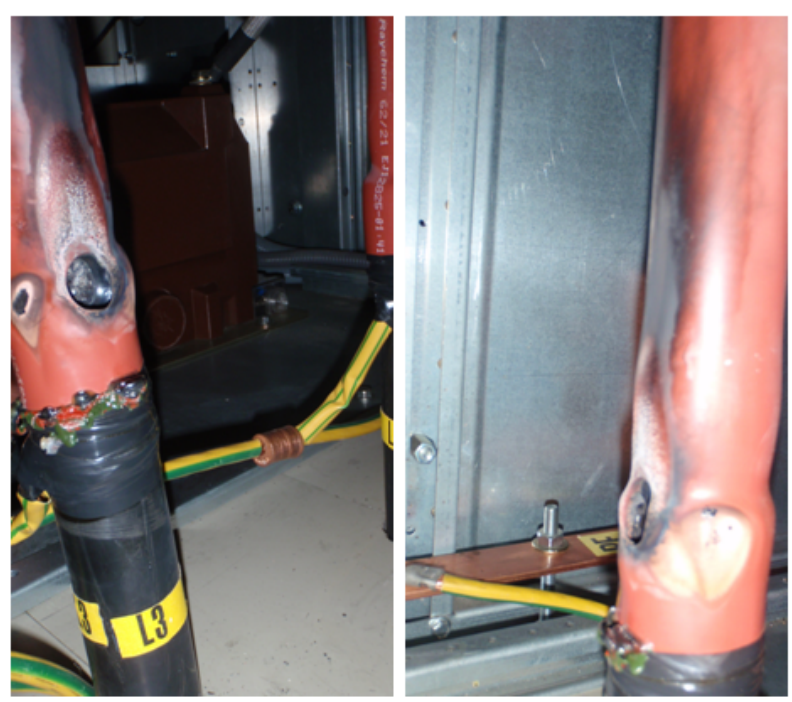

Figure 3: Phase to ground fault on end termination of supply cable

A breakdown of a surge arrester had also occurred under the events. Figure 4 shows the surge arresters with the broken one to the left. By looking at the broken surge arrester and the signs of heat, it is natural to assume that the amount of energy dissipated in the surge arrester was higher than its energy handling capability.

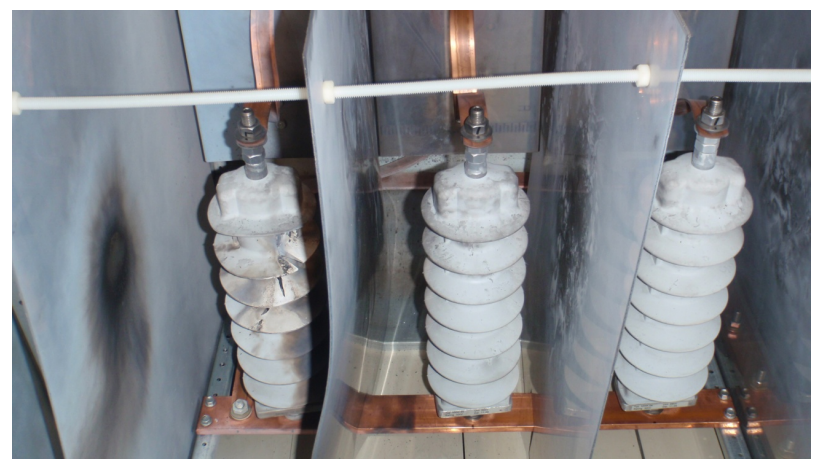

Figure 4: Broken surge arrester to the far-left

Signs of high temperatures and arcs were also seen other places in the rack of the $22 \mathrm{kV}$ busbar, which could be signs of a possible short-circuit due to a high voltage.

Damages did also occur in other places of the radial this day, which indicates that the phenomenon did not only take place locally in Grunnåi.

\subsection{The sequence of events}

By looking into the logs of the protection relays in Grunnåi and Seljord sub-station, it was discovered that several functionalities in each of the protection relays had started to account for triggering. Unfortunately the clocks in the protection relays were not synchronised, so it is impossible to determine which protection relay triggered first.

It is most likely to think that the whole sequence started with a breakdown in the end termination of the incoming cable in Grunnaii. The breakdown was most likely caused by a weakness in the end termination due an installation failure. This error may have caused a bad connection or a weakness in the insulation which led to heat generation and degradation of the insulation over longer period of time.

The presumed sequence of events was:

1. Earth circuit fault in Grunnåi due to a breakdown in the end termination of a incoming supply cables.

2. The protection relay in the Seljord sub-station detected the phase to ground fault and disconnected the Lønnestad radial from the rest of the grid in Seljord momentarily after the fault was detected.

3. The disconnection resulted in heavy imbalance of active power and reactive power in the now islanded radial.

4. The frequency in the grid increased rapidly since Grunnaii did not correct for the overproduction in the island.

5. The generator circuit breaker disconnected Grunnai from the grid, due to triggering of the overfrequency relay $(51 \mathrm{~Hz}$ and 0.1 seconds). This left the asynchronous generators in Sagbekken 1 and Sagbekken 2 and 3 alone in the island.

6. Sufficient amount of reactive power in the grid to initiate self-excitation. The self-excitation led to a successive voltage build-up, which resulted in significant over-voltages in the grid.

7. The high voltage led to a large voltage drop across the surge arresters in Grunnaii. The amount of energy dissipated in the surge arrester was higher than its energy handling capability. This caused one of the surge arresters to breakdown.

8. The high voltage exceeded the dielectric strength of air inside the rack of the busbars. The air became ionised and arcing occurred inside the rack. This arcing led to low impedance in the grid, and the process of self-excitation came to halt.

This is the presumed sequence of events, based on the damages and grid configuration. Following chapter presents simulations from the Lonnestad radial where different scenarios are carried out. 


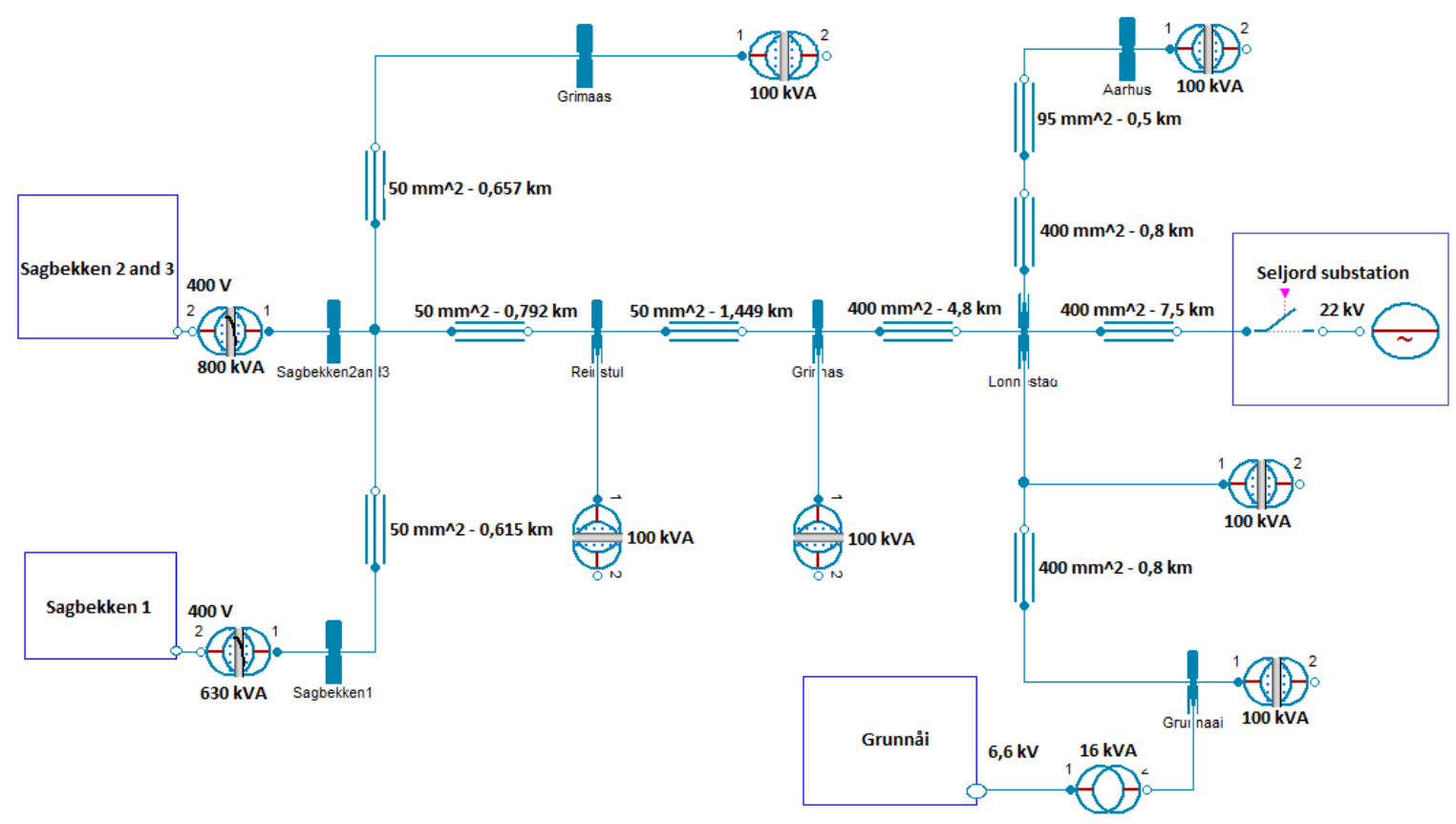

Figure 5: Overview of the Lønnestad radial

\section{Description of the grid}

For investigation of the over-voltage phenomena in Grunnaii power station, only the Lønnestad radial is of interest. This is the $22 \mathrm{kV}$ radial where the Grunnåi power station and Sagbekken power stations are connected. The radial is mainly built up with cables, where the total length of $22 \mathrm{kV}$ cables is $17.9 \mathrm{~km}$. An overview of the Lønnestad radial is shown in Figure 5. The total power consumption in the radial will vary throughout the day, but is assumed to be $250 \mathrm{~kW}$ with a power factor equal to 0.96 during the working hours.

\subsection{Grunnåi power station}

Grunnåi hydro power station is the largest power station in the Lqnnestad radial with a synchronous generator of $15.06 \mathrm{MW}$. The turbine is governed with an infinite droop control, which means that the power station runs at a constant power set-point independently of the electrical frequency in the grid. Figure 6 shows a picture of the synchronous generator inside the power station.

\subsection{Sagbekken power stations}

Sagbekken 1 and Sagbekken 2 and 3 are two micro power stations that utilise the water from the same river. Both of the power stations are equipped

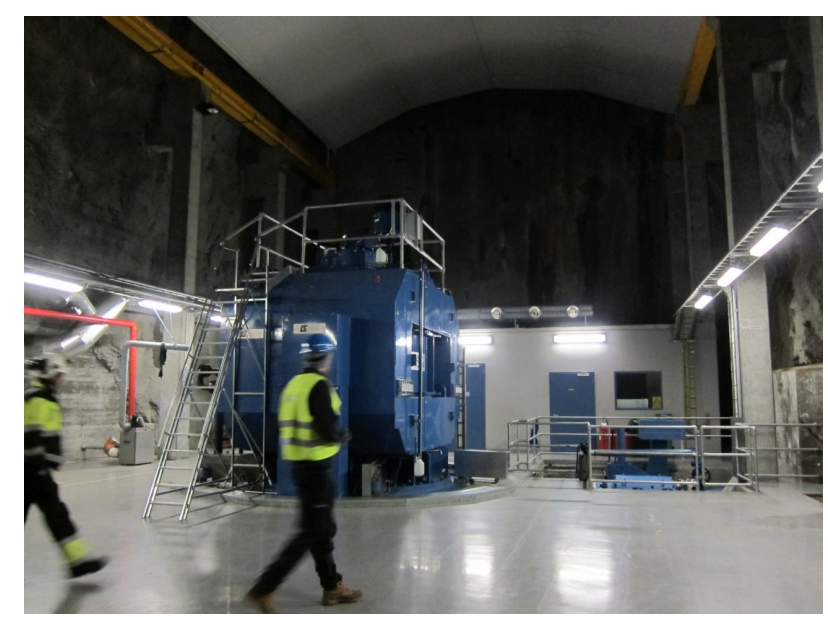

Figure 6: Grunnåi power station with its generator

with asynchronous generators with squirrel cage rotor, where Sagbekken 1 has three units with a total installed capacity of $400 \mathrm{~kW}$, and Sagbekken 2 and 3 has four units with a total installed capacity of $475 \mathrm{~kW}$.

Each of the powers stations is equipped with protection relays that operate a common generator circuit breaker in each station. Figure 7 shows the four generator units in Sagbekken 2 and 3. 


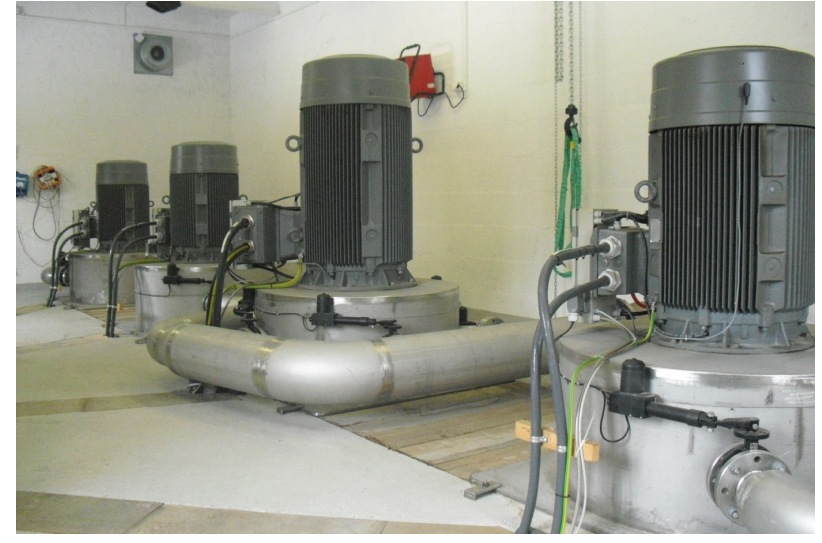

Figure 7: The four generator units in Sagbekken 2 and 3

\section{Power system simulations}

The power system of the Lønnestad radial was modelled and simulated using Modelica [7] as modelling language and Dymola[8] as simulation tool. Several models of the power system were created to simulate different scenarios. A small project library was build for the power system, containing the different power system models, main components, and subsystems developed for the models.

The power systems model developed for the $L \phi n$ nestad radial are based on the Electric Power Library[9] which is a commercial library developed by the Swedish company Modelon[10]. The library gives the opportunity to model, simulate, and analyse electric power systems, including $\mathrm{AC}$ three phase systems, AC one phase systems, and DC systems. The models can be used for both steady state and transient mode for simulation and initialisation.

Some components like the protection relays and RMS voltage sensors were not available in the Electric Power Library and were therefore created using the Modelica Standard Library [11].

The following sections will give you a brief introduction to the models used and the investigated effects. A more complete and thorough documentation is also available in [12].

\subsection{Simulation models}

Each of the power-station models consist of model for the generator-turbine unit and a protection relay unit. Figure 8 shows an example how the different power stations are build up in principle.

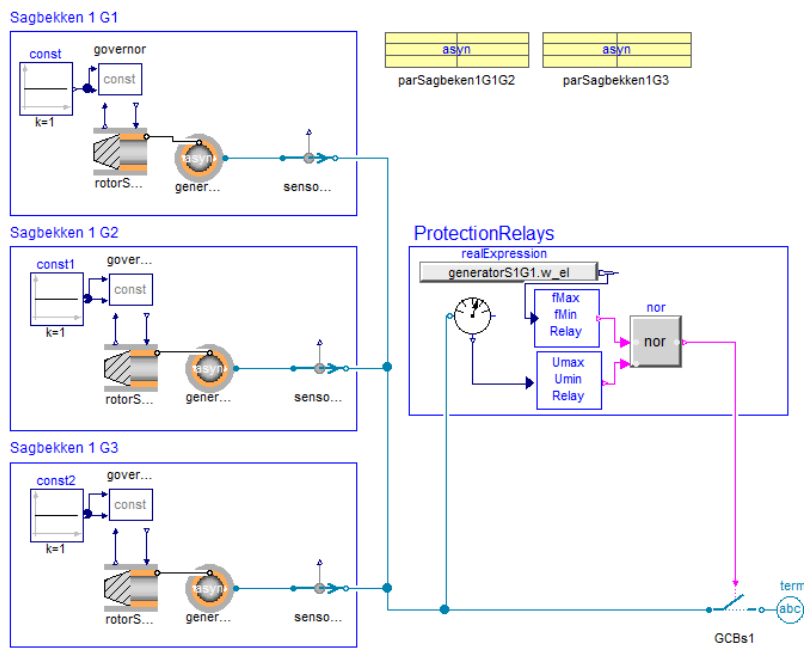

Figure 8: Sub-model Sagbekken 1

\subsection{Investigation of the self-excitation pro- cess}

To be able to investigate the process of selfexcitation with different grid configurations, the model in Figure 9 was created.

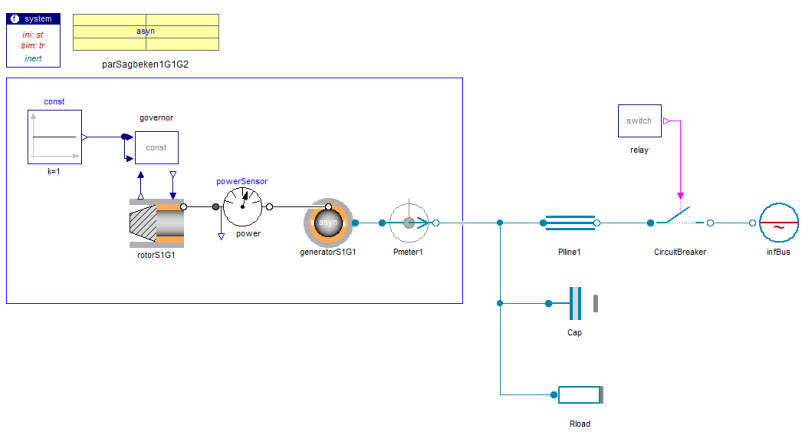

Figure 9: Model used for investigation of the selfexcitation process

The model consists of a $100 \mathrm{~kW}$ asynchronous production unit and an equivalent distribution line which is connected to an infinite grid. The investigation was carried out as sensitivity analysis where different loads and capacitors where compared in order to determine their impact on the system. At $t=1$ second the circuit breaker was opened, which brought the power plant into islanded grid operation with a given capacitive power and resistive load connected. 


\subsubsection{Self-excited induction generator without capacitors}

Figure 10 shows how the SEIG behaves when it is suddenly brought into islanded operation without capacitors connected to the generator terminals. Before disconnection it can be observed that the generator operates in steady state where it produces $98.4 \mathrm{~kW}$ with active power, and consumes $67.1 \mathrm{kvar}$ with reactive power. As the induction machine no longer is able to produce the main air-gap and winding leakage flux after the disconnection, it can be seen how the voltage reaches zero when the machine de-excites. Due to the constant mechanical torque, $T_{m}$, on the rotor, it can be seen in Figure 10 how the angular velocity, $\omega_{r}$, increases when the electrical torque, $T_{e}$, disappears:

$$
\frac{\mathrm{d} \omega_{r}}{\mathrm{~d} t}=\frac{T_{m}-T_{e}}{J}
$$
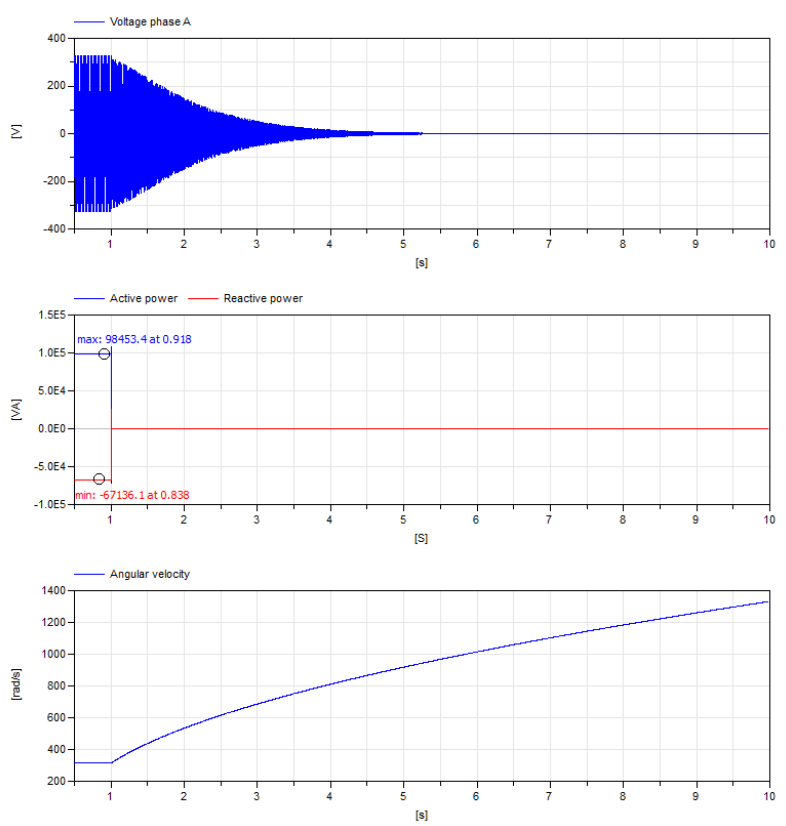

Figure 10: SEIG with no capacitor, disconnection at $t=1 s$

\subsubsection{Self-excited induction generator with ca- pacitors}

The unloaded SEIG's behaviour with different capacitors after a disconnection is shown in Figure 11. From the figure it can be seen that the SEIG needs at least $10 \mathrm{kvar}$ of capacitive power in shunt with the generator to initiate a successful voltage buildup after a disconnection. The figure also shows that a further increase of the capacitive power results in shorter time from the disconnection to the voltage build-up and a lower peak voltage. This is because larger capacitors provide the minimum amount of reactive power required for self-excitation at a lower angular velocity than smaller ones.
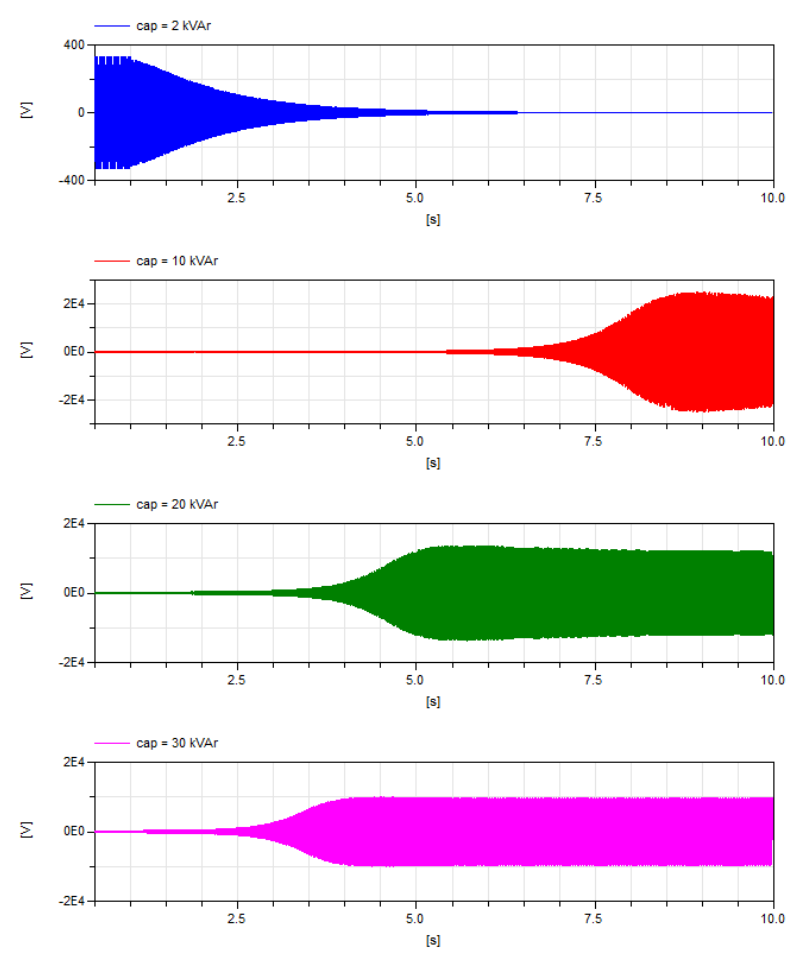

Figure 11: SEIG voltage with different capacitors, disconnection at $t=1 \mathrm{~s}$

\subsubsection{Self-excited induction generator with ca- pacitors and load}

To simulate a resistive load's impact on the SEIG, a sensitivity analysis was performed with different resistive loads. For all the different loading scenarios, a 30 kvar capacitor bank was connected in shunt with the generator terminals.

By comparing the $10 \mathrm{~kW}$ simulation in Figure 12 with the similar no-load simulation in Figure 11, it can be observed that the load has a considerable influence on the new operating point. The $10 \mathrm{~kW}$ load reduces the maximum over-voltage of the $100 \mathrm{~kW}$ generator from $10 \mathrm{kV}$ to $1.4 \mathrm{kV}$.

For the simulation with the $90 \mathrm{~kW}$ load, it can be observed that the load is too large to initiate the voltage build-up immediately after the disconnection. As the rotor accelerates, it can be seen that the self-excitation is initiated after $t=2.5$ seconds when 
the angular velocity is large enough for the capacitors.
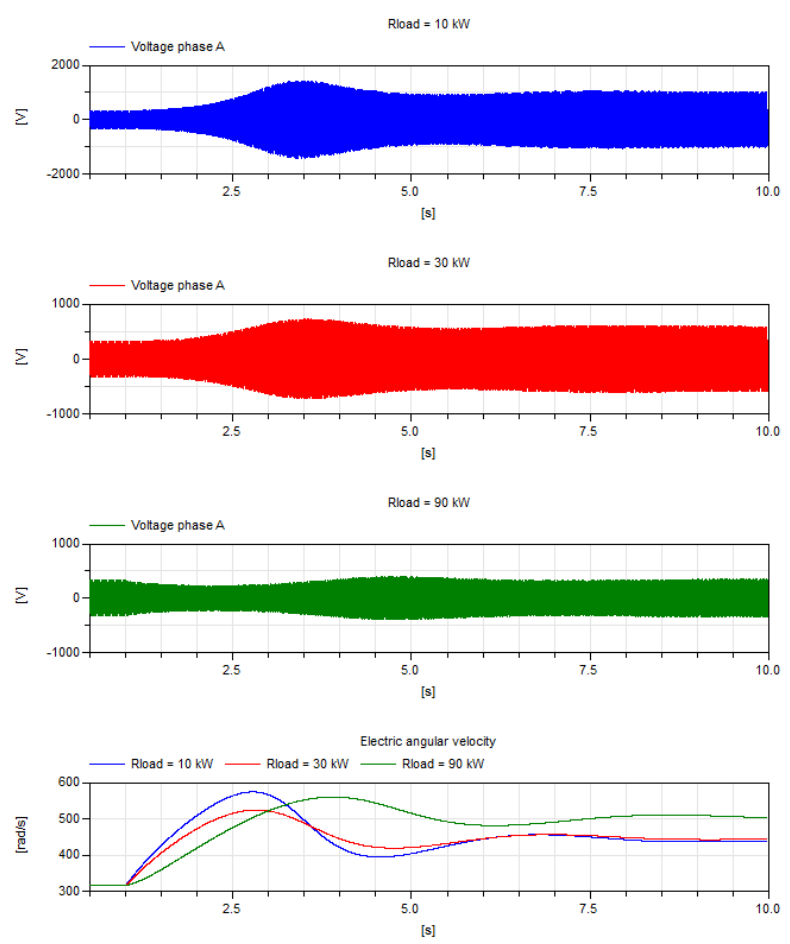

Figure 12: SEIG with 30 kvar capacitors and different loads, disconnection at $t=1 \mathrm{~s}$

\subsection{Simulation with phase to ground fault at Grunnåi}

In order to investigate the over-voltage that occurred at the $22 \mathrm{kV}$ busbar in Grunnai i on the $27^{\text {th }}$ July 2011, the simulation model in Figure 13 was created. At $t=1$ second a phase to ground fault occurs at phase $A$. Simultaneously as the phase to ground fault occurs, the circuit breaker in Seljord substation disconnects the Lonnestad radial from the rest of the grid due to momentary triggering settings in the protection relay.

Figure 14 shows how the voltages changes when the phase to ground fault occurs at phase A, causing the system to go from a balanced system to an unbalanced system. By looking at the figure it can be clearly seen that the radial has enough capacitive power and low enough load to initiate self-excitation process in the Sagbekken power stations once the Grunnåi power station is disconnected.

Figure 15 shows that it took 1.5 seconds from the phase to ground fault occurring at the Grunnai i power station before all the generators in the radial were dis-
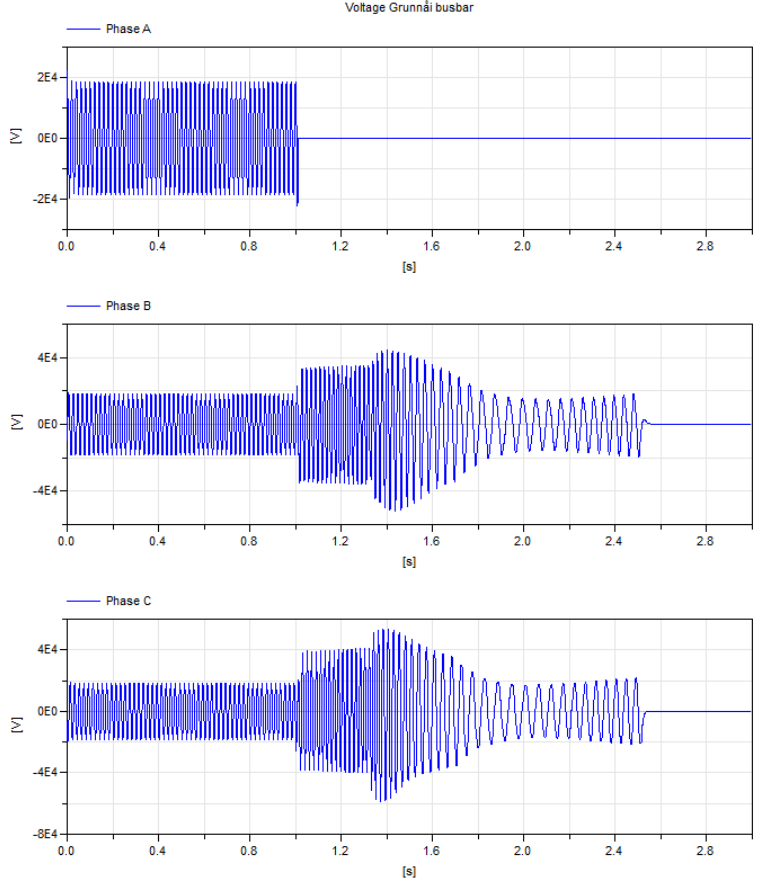

Figure 14: Voltage at Grunnåi busbar, phase to ground fault at $T=1 \mathrm{~s}$

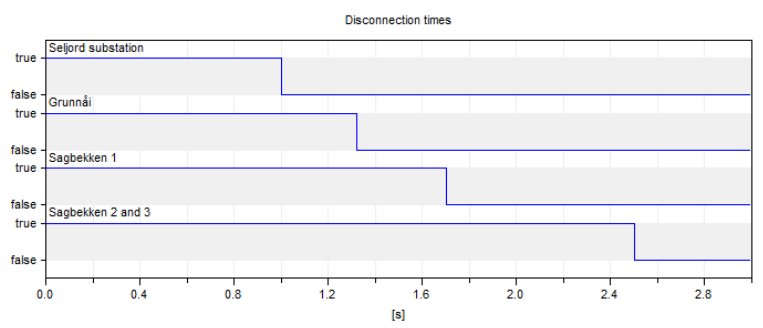

Figure 15: Disconnection times, phase to ground fault at $T=1 \mathrm{~s}$

connected. During this time the over-voltage reached its maximum value of $53.36 \mathrm{kV}$ and was continuously over $30 \mathrm{kV}$ for 0.7 seconds at phase $C$.

\section{Discussion}

The investigation of the self-excitation process shows how the dynamics of the generator changes when different capacitors and loads are connected to the generator terminals. For a generator running at no load with capacitors connected to the terminals, there exists a minimum speed for self-excitation to occur. If the capacitors do not provide sufficient excitation to initiate the self-excitation at the given speed, the loss of the utility grid causes a sudden in- 


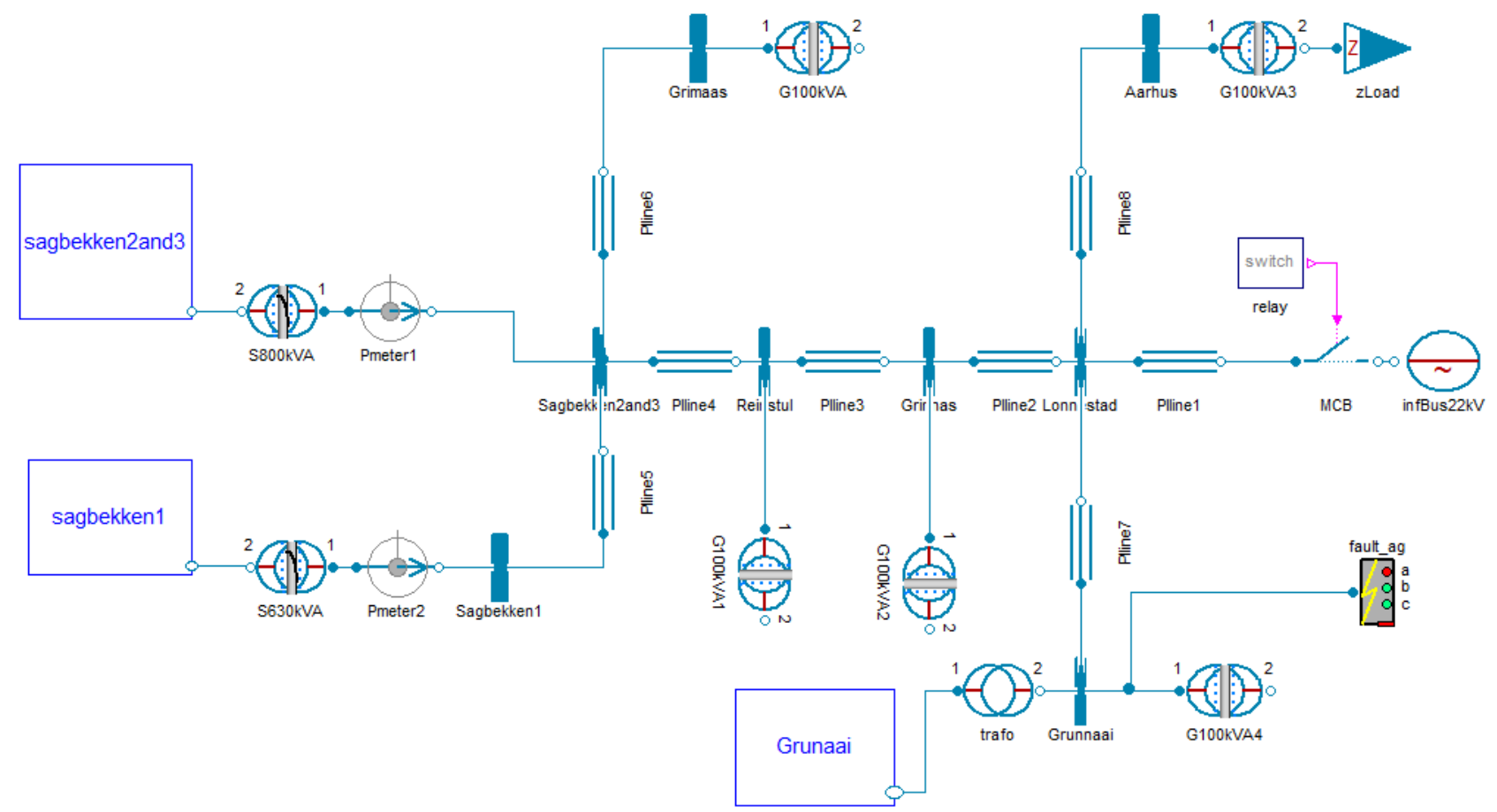

Figure 13: Model of Lønnestad radial with phase to ground fault

crease in the slope of the equivalent capacitor line seen by the generator [1]. This change may cause a complete or partial loss of the generator excitation. Due to this, the generator fails to produce an electromagnetic torque large enough to overcome the mechanical torque, which results in acceleration of the rotor.

Unless the residual flux is lost, the self-excitation can be initiated when the angular velocity has increased such that the reactive power from the capacitors is sufficient. Once the process of self-excitation is initiated, the terminal voltage starts to build up. The generator reaches its new stable operating point when the dynamic magnetisation line of the generator intersects the linear capacitor line.

For asynchronous generators connected to a utility grid with much reactive power in form of capacitors or cables, it is crucial with quick detection and low trigger time for over-frequencies to avoid unwanted over-voltages.

The simulations shows that the reactive power in the grid is great enough initiate self-excitation that results in harmful over-voltages, independently of whether the load is connected or not. It is seen that the voltage build-up happens quickly. It takes below 0.4 seconds from the radial is brought into islanded operation to the voltage reaches its peak value.

Significant over-voltages can also occur when a phase to ground fault arise at Grunnåi busbar. Regardless of whether Grunnai power station is connected or a phase to ground fault arise, the selfexcitation of the Sagbekken stations will result in harmful over-voltages. For all the simulations, the magnitude and length of the over-voltages are greater than the thermal stability limit of the surge arresters in Grunnåi power station.

Correct parameters for the protection relays are essential for providing sufficient protection of the grid. This is also the easiest way to protect the Lønnestad radial against harmful over-voltages. Simulations show that the peak value of the angular velocity can vary dependent on the load scenario. Correct parameters for detection of over-voltages are therefore most important for the protection relays.

\section{Conclusion}

This paper investigates the system dynamics in the Lønnestad radial when it is brought into islanded operation. Modelling and simulation of the transient behaviour of an asynchronous generator is a fairly complex task that requires good knowledge of electric machinery and dynamic systems. Due to this, there is often a lack of knowledge in small utility companies when it comes to the asynchronous gen- 
erator.

The asynchronous generator has the opportunity to operate as a standalone unit if the amount of reactive power in the cables or capacitors is sufficient. For the Lønnestad radial, it was proven that the amount of reactive power in the grid is large enough to initiate self-excitation of all the seven asynchronous generators in the radial.

The self-excitation leads to fast voltage build-ups that results in a harmful over-voltage in the distribution grid. For the simulations with load connected, it was observed that the over-voltage in the distribution grid reached its maximum voltage of circa $50 \mathrm{kV}$, only 0.4 seconds after the radial was brought into islanded operation.

This is a type of over-voltage that requires a great deal of knowledge regarding self-excitation to ensure good protection of the grid. Normal protection methods as surge arresters will not be adequate, since these are designed to protect against surge voltages, and not transient over-voltages with several seconds duration. Simulations performed in this paper show that it is crucial with correct protection parameters in the Sagbekken stations to protect equipment in the Lфnnestad radial against over-voltages caused by the generators. To avoid unwanted voltage buildups, correct parameters for over-voltage detection is the most important protection. It is recommended to have momentarily disconnection when the voltage exceeds a given value.

\section{Acknowledgements}

The work was carried out as part of the Master thesis of Håkon Molland Edvardsen [12] in cooperation with Skagerak Energi, Porsgrunn, Norway and under supervision of Dietmar Winkler.

\section{References}

[1] L. Tang and R. Zavadil. "Shunt capacitor failures due to windfarm induction generator self-excitation phenomenon". In: IEEE Transactions on Energy Conversion 8.3 (1993), pp. 513-519. DOI: 10 . 1109 / 60 . 257067. URL: http : / / ieeexplore . ieee . org / stamp / stamp . jsp ? tp = \&arnumber $=$ 257067.
[2] Robert H. Park. "Two-reaction theory of synchronous machines generalized method of analysis-part I'. In: Transactions of the American Institute of Electrical Engineers 48.3 (1929), pp. 716-727. DOI: 10 . $1109 / \mathrm{T}-$ AIEE . 1929 . 5055275. URL: http : / / ieeexplore . ieee . org / stamp / stamp . jsp?tp=\&arnumber $=5055275$.

[3] F. Sulla. Island Operation with Induction Generators: Fault Analysis and Protection. Department of Measurement Technology and Industrial Electrical Engineering, Lund University, 2009. ISBN: 9789188934512. URL: http : / / books . google . no / books ? id= PiQbtwAACAAJ.

[4] Dawit Seyoum, C Grantham and F Rahman. "Analysis of an isolated self-excited induction generator driven by a variable speed prime mover". In: Proc. AUPEC. Vol. 1. 2001, pp. 49-54.

[5] Ned Mohan. Electric Power Systems: A First Course (Coursesmart). Wiley, 2012. ISBN: 1118074793.

[6] Jan Machowski, Janusz Bialek and Dr Jim Bumby. Power System Dynamics and Stability. Wiley, 1997. ISBN: 0471956430.

[7] Modelica Association. Modelica - A Unified Object-Oriented Language for Physical Systems Modeling - Language Specification. Version 3.2. 2012.

[8] Dassault Systèmes. Dymola. 2013. URL: http://www.dymola.com.

[9] Modelon. Electric Power Library. 2013. URL: http : / / www . modelon . com / products / modelica - libraries / electrical power-library/.

[10] Modelon. Homepage. URL: http : / / www . modelon. com.

[11] Modelica Association. Modelica - Free library from the Modelica Association. 2010. URL: https : / / github . com/modelica / Modelica.

[12] Håkon Molland Edvardsen. "System dynamics of asynchronous generators at islanded grid operation". MA thesis. Telemark University College, 2013. DOI: 2282 / 2125. URL: https : //teora . hit . no/handle/2282/ 2125 . 